Agrotrópica 33(1): 49 - 54. 2021.

Centro de Pesquisas do Cacau, Ilhéus, Bahia, Brasil

\title{
REGISTRO DE Lasiodiplodia theobromae EM FRUTOS ABORTADOS DE COQUEIRO NO SERTÃO DA BAHIA, BRASIL
}

\author{
Juliana Silva Nascimento Souza ${ }^{1}$, Maiara Araújo Lima dos Santos², Nadja Santos Vitória ${ }^{1}$ \\ ${ }^{1}$ Universidade do Estado da Bahia, Campus VIII, Departamento de Educação, Colegiado de Biologia Rua do Gangorra, 503, \\ 48608-240, Bairro Alves de Souza, Paulo Afonso, Bahia, Brasil, juliana.jsn@hotmail.com \\ ${ }^{2}$ Programa de Pós-Graduação em Biologia de Fungos, Universidade Federal de Pernambuco, Recife, 50740-570, \\ Pernambuco, Brasil.
}

Lasiodiplodia theobromae (Pat.) Griff. \& Maubl. é um fungo mitospórico, cosmopolita e oportunista, ocorrendo em uma ampla gama de hospedeiros. Os danos causados por esse fungo em Cocos nucifera L., palmeira popularmente conhecida como coqueiro, são diversos. Microfungos em espécies de Arecaceae são encontrados no tronco, folha, pecíolo, fruto, inflorescência e raque, acomodando uma rica variedade de táxons, incluindo endofíticos, sapróbios e fitopatógenos. O presente estudo objetivou analisar os sinais na superfície dos frutos de coqueiro abortados, provenientes de plantio comercial na Fazenda Baixa do Penedo, no munícipio de Rodelas, Bahia, visando a identificação das estruturas existentes. A coleta foi realizada no mês de agosto de 2014. Cachos de frutos abortados ainda presos à planta foram coletados de 10 indivíduos. No laboratório, fragmentos de esporóforos foram retirados e montados entre lâmina e lamínula, utilizando água e lactofenol com adição de corante azul de algodão. Além disso, foi realizado teste de patogenicidade. Todo material examinado foi mensurado, fotomicrografado e identificado. As características morfológicas permitiram identificar o fungo como L. theobromae. Esse microrganismo é um problema limitante para a fruticultura tropical.

Palavras-chaves: Taxonomia, Arecaceae, Semiárido.

Record of Lasiodiplodia theobromae in aborted fruits of coconut in the hinterland of Bahia, Brazil. Lasiodiplodia theobromae (Pat.) Griff. \& Maubl. is a mythosporic, cosmopolitan, and opportunistic fungus, occurring in a wide range of hosts. The damage caused by this fungus to Cocos nucifera L., a palm popularly known as coconut tree, is diverse. Microfungi in species of Arecaceae are found in the trunk, leaf, petiole, fruit, inflorescence and rake, accommodating a rich variety of taxa, including endophytes, saprobes and phytopathogens. The present study aimed to analyze the signs on the surface of the aborted coconut fruits from commercial planting at Farm Baixa do Penedo, in the municipality of Rodelas, Bahia, in order to identify the existing structures. The collections were carried out in the months of June, July, August, October, November and December / 2014. Bunches of aborted fruits still attached to the plant were collected from 10 individuals. In the laboratory, fragments of sporophores were removed and mounted between slide and cover slip, using water and lactophenol with the addition of blue cotton dye. In addition, a pathogenicity test was performed. All material examined was measured, photomicrographed and identified. The morphological characteristics allowed to identify the fungus as L. theobromae. This microorganism is a limiting problem for tropical fruit growing.

Key words: Taxonomy, Arecaceae, Semiarid. 


\section{Introdução}

Lasiodiplodia theobromae (Pat.) Griff. \& Maubl. é um fungo do filo Ascomycota, cosmopolita, oportunista e polífago, ocorrendo em cerca de 500 espécies de plantas (Vitória et al., 2012). Possui reduzida especialização patogênica, sendo, em geral, associado a processos patogênicos em plantas estressadas e submetidas a ferimentos naturais ou provocados (Olunloyo \& Esuruoso, 1975; Punithaligam, 1976).

Esse fungo pode sobreviver na atmosfera, nos tecidos vegetais vivos ou mortos, podendo ser disseminado pelos instrumentos de poda, vento e insetos, penetrando no hospedeiro pelas aberturas naturais ou por meio de práticas culturais (Oliveira et al., 2013). É responsável por causar doenças em mangueiras (Mangifera indica L.), cajaraneiras (Spondias dulcis Sol. ex Parkinson), cajueiros (Anaccardium occidentale L.), abacateiros (Persea americana Mill.), coqueiros (Cocos nucifera L.), citros (Citrus sp.), frutos de graviola (Annona muricata L.), jambeiros (Syzygium jambos (L.) Alston), pinha (Annona squamosa Delile), jenipapo (Genipa americana L.), em plantas ornamentais, palma forrageira (Opuntia cochenillifera (L.) Mill.), em sementes de mamona (Ricinus communis L.) e de milho (Zea mays L.), em eucalipto argentino (Eucalyptus globulus Labill.), jaqueira (Artocarpus heterophyllus Lam.), mandioca (Manihot esculenta Crantz), videira (Vitis sp.), figueira (Ficus sp.), meloeiros (Cucumis melo L.), goiabeiras (Psidium guajava L.), sapotizeiros (Manilkara zapota (L.) P. Royen.), entre outras (Oliveira et al., 2013; Freire et al., 2004).

A capacidade de L. theobromae de infectar frutos coloca esse microrganismo dentre os mais eficientes patógenos propagados por meio de sementes, causando problemas pós-colheita (Freire et al., 2004). Em C. nucifera (coqueiro), os danos provocados por esse fungo são a queima das folhas e a podridão basal dos frutos em pós colheita (Halfeld-Vieira e Nechet, 2005).

O coqueiro (C. nucifera) possui grande importância mundial, devido à geração de empregos e renda em vários países do globo, além de sua versatilidade de uso, pois os frutos podem ser consumidos in natura ou industrializados na forma de mais de 100 produtos e subprodutos, além de suas outras partes, como folhas que podem ser usadas na produção de utensílios artesanais (Santos, 2017).

No município de Rodelas, estado da Bahia, foi constatado o abortamento de frutos em plantas de coqueiro anão verde, provenientes de plantio comercial na Fazenda Baixa do Penedo, localizado no povoado Penedo. Com o intuito de investigar as possíveis causas, esse estudo objetivou analisar os sinais na superfície dos frutos abortados, visando a identificação das estruturas presentes.

\section{Material e Métodos}

A pesquisa foi realizada na Fazenda Baixa do Penedo (09 24' 0,35"'S e $38^{\circ} 12^{\prime}$ '76,6”'W, $\left.221 \mathrm{~m}\right)$ localizado no povoado Penedo, em Rodelas, Bahia. Limitando-se a Leste com os municípios de Glória e Paulo Afonso, a Sul com Jeremoabo, a Oeste com Macururé e Chorrochó e a Norte com o estado de Pernambuco. A agricultura é a principal fonte de renda para os moradores desse povoado. Utilizam principalmente a monocultura do coco, gerando emprego e renda para a comunidade (Figura 1).

A coleta foi realizada em agosto de 2014, período em que a região apresentava temperatura mínima de $17,60{ }^{\circ} \mathrm{C}$ e máxima de $27,56{ }^{\circ} \mathrm{C}$, com precipitação 0 , segundo dados do Agritempo (https:// www.agritempo.gov.br/agritempo/index.jsp). Foram coletados cachos de frutos ainda presos à planta de 10 indivíduos escolhidos aleatoriamente, com uma distância de no mínimo oito metros entre cada indivíduo. $\mathrm{O}$ material foi acondicionado em sacos de papel tipo Kraft de $2 \mathrm{~kg}$. As amostras foram analisadas no Laboratório de Ciências da Universidade do Estado Bahia - UNEB, Campus VIII, Paulo Afonso-BA (Figura 2).

A análise topográfica do material coletado foi feita em microscópio estereoscópico. Fragmentos de esporóforos foram removidos com o auxílio de uma agulha de ponta fina (tipo insulina) e montados entre lâmina e lamínula utilizando água e lactofenol com adição de corante azul de algodão, como meio de montagem. Além disso, secções transversais dos esporóforos foram realizadas com o auxílio de lâminas de barbear e efetuada à mão livre para a observação da estrutura reprodutiva. As preparações foram 


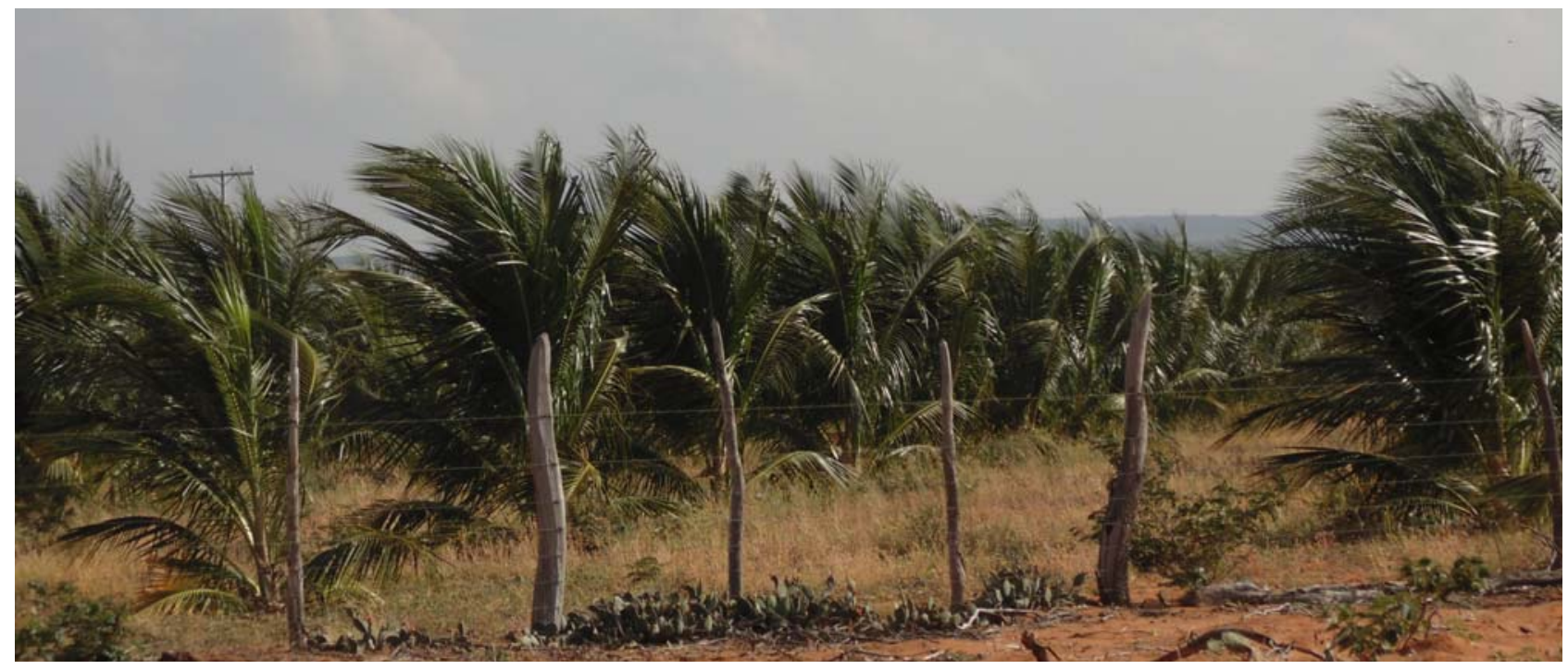

Figura 1. Plantação de coqueiro na Fazenda Baixa do Penedo, povoado Penedo, Município de Rodelas, Estado da Bahia. Foto: Vitória, N.S.

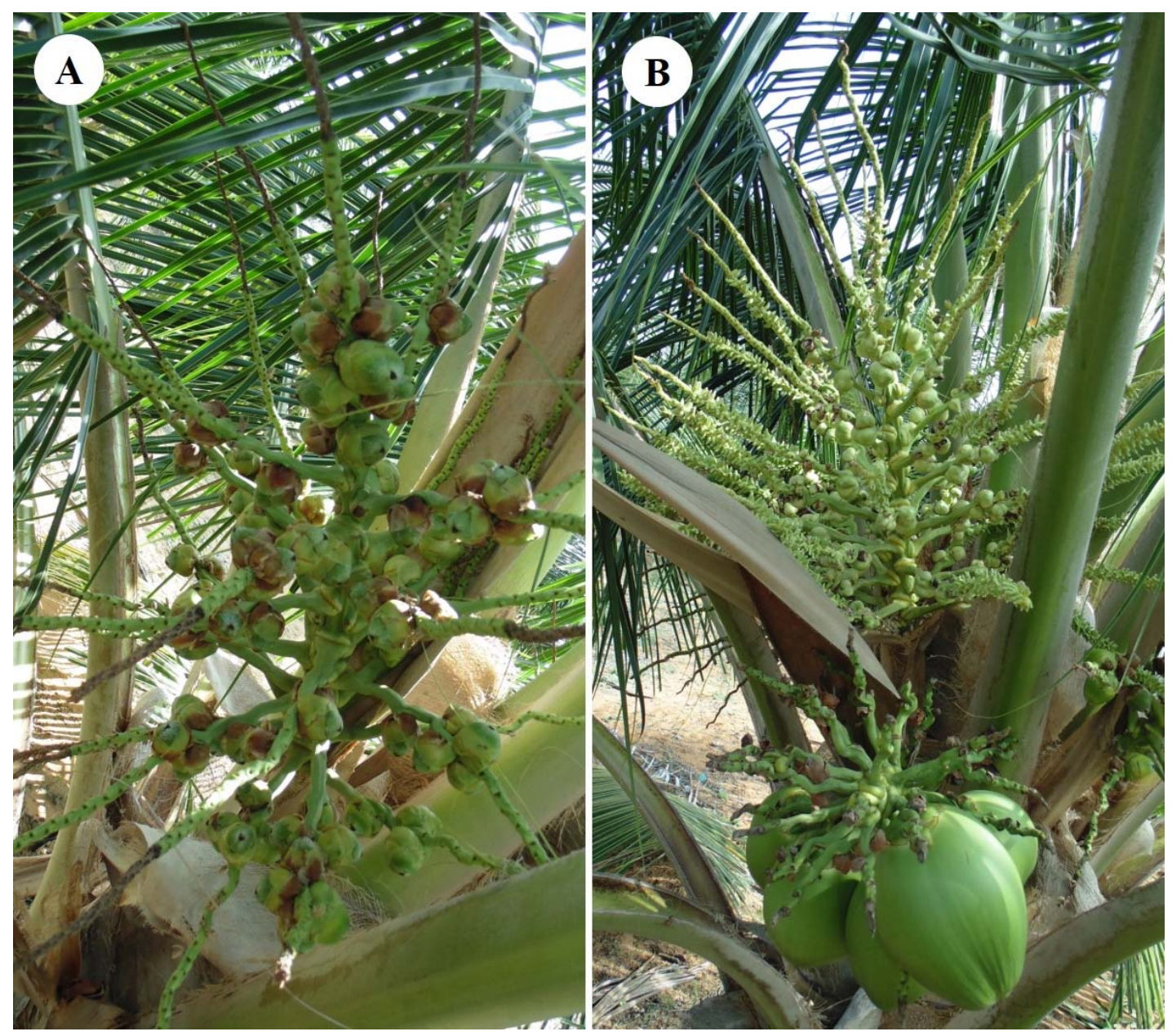

Figura 2. A-B. Cachos de frutos abortados ainda presos à planta. Fotos: Vitória, N.S. 
observadas ao microscópio de luz (Zeiss) em diversos aumentos para caracterização das estruturas morfológicas, as quais foram medidas com auxílio de um micrômetro ocular. Foram realizadas fotomicrografias e a identificação taxonômica do material por meio de literatura especializada (Barnett \& Hunter, 1998; Sutton, 1980).

Para o teste de patogenicidade o himênio dos esporóforos foram removidos ( $\mathrm{n}=10$ conidiomas) e diluídos em $10 \mathrm{ml}$ de água destilada autoclavada. Alíquotas de $0,5 \mathrm{ml}$ da suspensão foram depositadas em folíolos e raques foliares sadios de C. nucifera e em seguida foram feitas câmaras úmidas em placas de Petri. As placas (câmaras úmidas) foram incubadas $\mathrm{a} \pm 28{ }^{\circ} \mathrm{C}$ durante 12 dias. Nas testemunhas, também foram feitas câmaras úmidas, utilizando a mesma metodologia, no entanto, não havia himênio do fungo nas alíquotas da suspensão, apenas água destilada autoclavada (Figura 3). O ensaio foi conduzido com duas repetições por tratamento. Todas as placas foram acompanhadas diariamente.

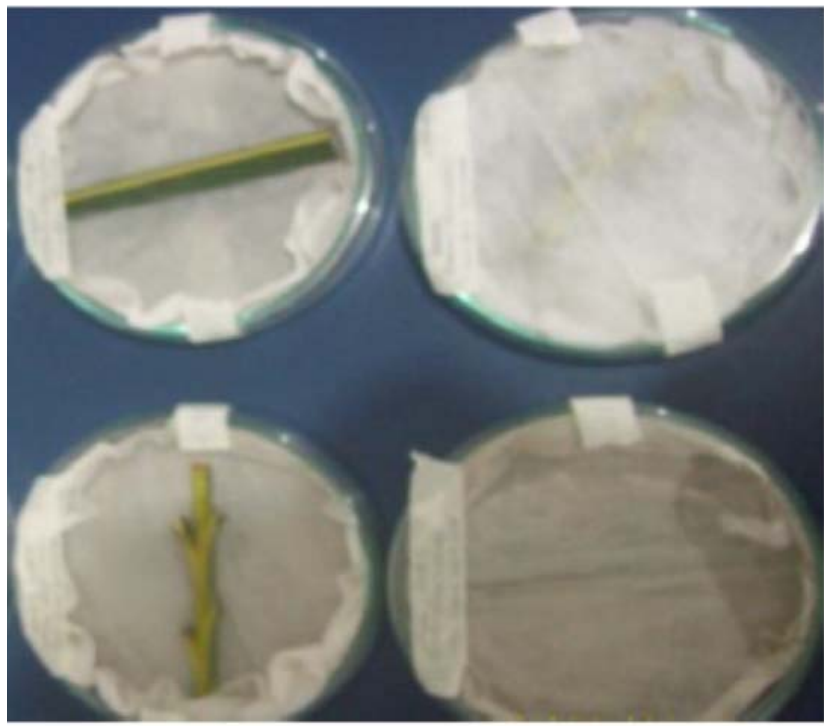

Figura 3. Raque e folíolo sadios de C. nucifera em placas de Petri (câmaras úmidas) após o depósito de alíquotas com a suspensão de himênios nos substratos. Foto: NASCIMENTO, J.S.

\section{Resultados e Discussão}

Os frutos coletados na plantação apresentavam conidiomas estromáticos picnidiais, negros, na superfície do substrato, com conídios a princípio ovoides, hialinos e unicelulares, mas tornando-se bicelulares, de coloração marrom escura e estrias longitudinais na maturidade, medindo 21-32,5 x 15 - 20 $\mu \mathrm{m}$ (Figura 4).

As características morfológicas permitiram identificar o fungo como L. theobromae, um Ascomycota anamórfico, ou seja, mitospórico, da família Botryosphaeriaceae, característico das regiões tropicais e subtropicais. Fatores como temperatura, umidade e luminosidade favorecem o crescimento desse patógeno, sendo temperaturas altas em torno de $27^{\circ} \mathrm{C}$ a $33^{\circ} \mathrm{C}$ mais propícias para o seu desenvolvimento (Melo, 2012). Esse microrganismo pode ocasionar diferentes doenças, como a morte descendente, cancro perene, gomose, manchas foliares, podridões de frutos, morte em culturas perenes e lenhosas e plantas ornamentais, como também em espécies florestais e introduzidas (Rêgo, 2018). De acordo com Cysne, Viana e Craveiro (2006), L. theobromae é um problema limitante para a fruticultura tropical. Segundo Kimati et al., 2011 citado por Moers et al., 2012), doenças em plantas causadas por patógenos como L. theobromae, ocasionam grandes prejuízos, que podem levar a perdas de $30 \%$ a cada ano da produção agrícola mundial.

Dez dias após o depósito de alíquotas da suspensão dos himênios de L. theobromae foi possível observar os primeiros sinais. Nenhuma das testemunhas desenvolveu estruturas reprodutivas do fungo. Foram realizados cortes histológicos a mão livre dos folíolos infectados para visualização e caracterização dos conidiomas e conídios que confirmaram a identificação do patógeno (Figura 5).

De acordo com Santos (2017) a infecção ocorre principalmente nas folhas inferiores, que são consideradas mais velhas, e estas lesões internas na ráquis progridem do ápice para a base atingindo a bainha e o estipe, resultando na exsudação de goma e necroses da base dos folíolos e, abaxialmente, em rachaduras da ráquis lesionada e bainha causando a morte dos tecidos foliares, a seca dos folíolos e de toda a folha, o que leva a perda expressiva de área fotossintética gerando a morte das folhas mais velhas, e como consequência deixa os cachos sem sustentação física e fisiológica, que acarreta na queda prematura dos frutos.

Oliveira et al. (2013) discutem que adotar medidas preventivas são necessárias, sobretudo a prática de 


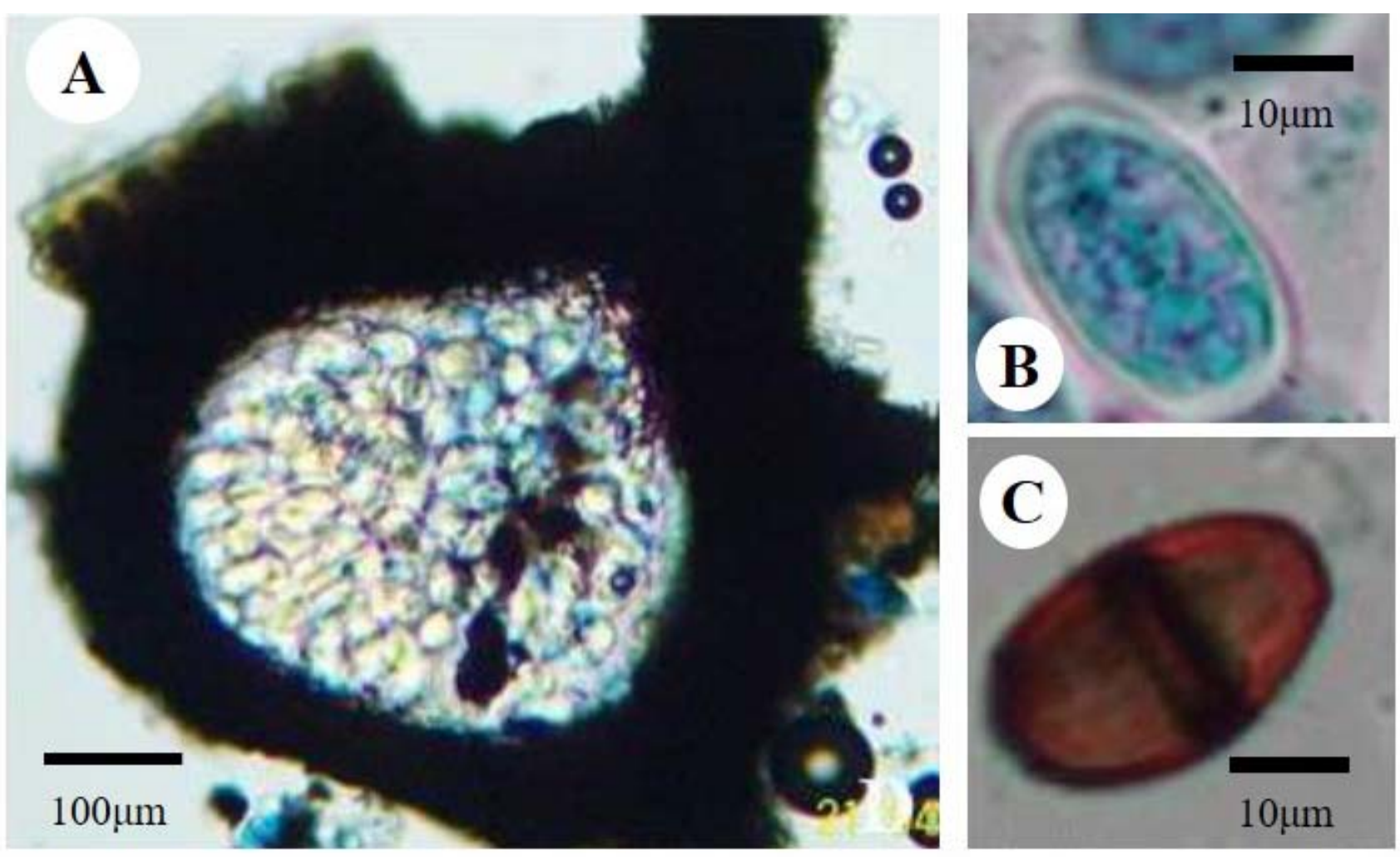

Figura 4. A. Conidioma estromático picnidial. B. Conídio jovem, asseptado e hialino. C. Conídio maduro, bicelular, marrom escuro, com estrias longitudinais. Foto: NASCIMENTO, J.S.
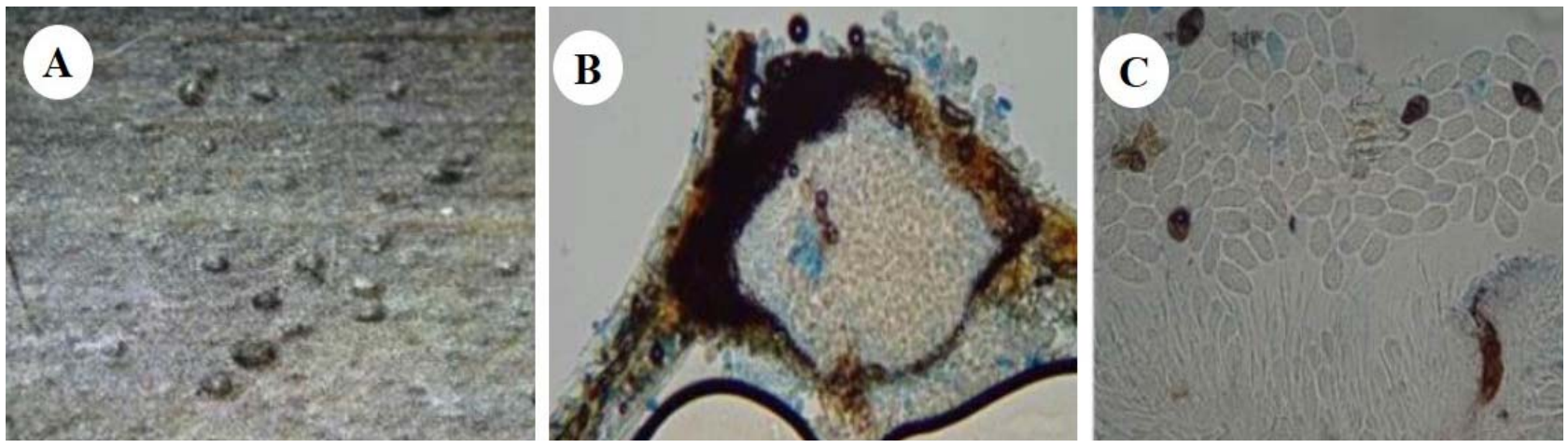

Figura 5. A. Folíolo infectado após depósito de alíquotas da suspensão dos himênios de L. theobromae. B. Secção transversal do conidioma no folíolo infectado. C. Conídios.

podas de limpeza, com a retirada dos ramos secos, protegendo as partes das plantas comprometidas e podadas, com uma pasta cúprica; desinfestação das ferramentas de poda com uma solução de hipoclorito de sódio diluída em água na proporção de 1:3; a eliminação dos restos de cultura; erradicação de todas as plantas mortas ou que apresentem a doença em estádio avançado; controle dos insetos que possam causar ferimentos às plantas e evitar o estresse hídrico e nutricional da planta.

Estudos sobre o fungo $L$. theobromae são relevantes, a fim de compreender melhor a interação hospedeiro-patógeno-ambiente (Oliveira et al., 2013). Na presente pesquisa, estudos nesse sentido não foram realizados, embora sejam necessários. No entanto o objetivo proposto foi alcançado, pois foi realizada a 
análise dos sinais na superfície dos frutos de $C$. nucifera abortados na Fazenda Baixa do Penedo em Rodelas e a identificação do fungo encontrado no material coletado.

\section{Conclusão}

Lasiodiplodia theobromae é um ascomiceto assexual, fitopatógeno com uma ampla gama de hospedeiros, incluindo a palmeira C. nucifera que se mostra como um bom substrato para a colonização de fungos. Nesta pesquisa, a identificação morfológica deste patógeno foi de grande relevância para a constatação dos danos causados por L. theobromae nos frutos imaturos de coqueiros provenientes do plantio comercial da Fazenda Baixa do Penedo, em Rodelas, sertão da Bahia.

\section{Agradecimentos}

Os autores agradecem a Universidade do Estado da Bahia, Campus VIII pela estrutura para realização das atividades laboratoriais e aos colegas Thaísa Danielly, Eveline Araújo e Nilo Gabriel pelas colaborações. Agradecemos também, ao senhor Izael Silva, proprietário da Fazenda onde foi realizada a pesquisa.

\section{Literatura Citada}

BARNETT, H. L.; HUNTER, B. B. 1998. Illustrated Genera of Imperfect Fungi. 4th Edition, APS Press, St. Paul. 218p.

CYSNE, A. Q.; VIANA, V. V.; CRAVEIRO, E. R. 2006. Avaliação de meios de cultura para crescimento e esporulação de Lasiodiplodia theobromae. In: Encontro de iniciação científica da Embrapa Agroindústria Tropical, 4. 2006, Fortaleza. Resumos. Fortaleza, CE. Embrapa Agricultura Tropical. 104p.

FREIRE, F. C. O. et al. 2004. Novos hospedeiros do fungo Lasiodiplodia theobromae no estado do Ceará. Comunicado Técnico $\mathrm{N}^{0}$ 91. Fortaleza. Embrapa Agroindústria Tropical.
HALFELD-VIEIRA, B. A.; NECHET, K. L. 2005. Queda de Frutos em Coqueiro Causada por Lasiodiplodia theobromae em Roraima. Fitopatologia Brasileira 30(2):203.

MELO, L. G. de L. 2012. Avaliação de parâmetros epidemiológicos da podridão por Lasiodiplodia em uva nas cultivares Itália uscat e Thompsom seedless. Dissertação Mestrado. Universidade Rural de Pernambuco, Recife. 51p.

MOERS, E. M. et al. 2012. Levantamento de doenças na cultura do crambe (Crambe abyssinica Hochst) na região oeste do Paraná. Scentia Agraria Paranaensis 11(1):35-48.

OLIVEIRA, M. Z. A. de, et al. 2013. Fungo Lasiodiplodia theobromae: um problema para agricultura baiana. Bahia Agrícola 9(2):24-29.

OLUNLOYO, O. A.; ESURUOSO, O. I. 1975. Lasiodiplodia floral shoot dieback disease of cashew in Nigeria. Plant Disease Reporter 59:176-179.

PUNITHALIGAM, E. 1976. Botryodiplodia theobromae. CMI Description of pathogenic fungi and bacteriano. $\mathrm{N}^{\circ}$ 519. Commonwealth Mycological Institute, Surrey.

RÊGO, T. J. S. 2018. Espécies de Lasiodiplodia associadas à morte descendente da videira no Nordeste do Brasil e diversidade genética de Lasiodiplodia theobromae. Tese Doutorado. Universidade Federal de Pernambuco, Recife, PE. 96p.

SANTOS, P. H. D. 2017. Patogenicidade e caracterização morfomolecular de fungos Botriosphaeriaceos associados ao coqueiro e filogeografia de Lasiodiplodia theobromae. Tese Doutorado. Universidade Estadual do Norte Fluminense Darcy Ribeiro, Campos dos Goytacazes, Rio de Janeiro. 86p.

SUTTON, B. C. 1980. The Coelomycetes. Commonwealth Mycological Institute, Kew, Surrey, England, U.K.

VITÓRIA, N. S. 2012. Diversidade de Ascomycota em palmeiras nativas e exóticas em áreas de Mata Atlântica. Tese Doutorado. Universidade Federal de Pernambuco, Recife, PE. 220p. 